\title{
Cien años de guerra por Martí *
}

\author{
Ádám Anderle \\ Universidad Attila József \\ Szeged, Hungría
}

El ensayo presenta las dos interpretaciones político-históricas antagónicas: la versión norteamericana y cubana actuales. En vez de una revisión detallada de la historiografía larga de cien años se analizan dos ensayos prototípicos: C. Ripoll (de Pittsburg) y Salvador Morales (de La Habana), para presentar las mutuas y antagónicas preocupaciones y las apologías de este tipo de literatura. En la segunda parte del ensayo el autor plantea - en forma de hipótesis-algunas interrogantes, con la sugerencia de buscar nuevas interpretaciones para entender la relación entre la obra martiana y la política actual del régimen de Fidel Castro. "El sincretismo político", "la interferencia política" entre la obra martiana y el marxismo leninismo en la ideología fideliana, son las nociones nuevas de esta interpretación, con la que se entienden mejor los problemas y temas concretos de Cuba: el carácter del poder, las características del Partido Comunista de Cuba, etc., que nos muestran un poder populista caribeño original "sincrético".

A principios de la década de los 70, cuando los partidos comunistas de los países socialistas europeos de entonces vivían uno de los períodos de enemistad - y discusiones ideológicas regularmente repetidas- en cuanto a sus relaciones con Cuba, el Partido Socialista Obrero Húngaro (en adelante, $\mathrm{PSOH}$ ), deseando comprender la esencia de los conflictos con los "camaradas" cubanos, encargó unas amplias investigaciones sobre Cuba. El material de estas investigaciones se publicó en una edición "cerrada" del PSOH, en cuatro tomos. Una de las preguntas planteadas en este trabajo era: ¿quién es José Martí, a quien los cubanos, entre ellos el mismo Fidel Castro, hacen referencia con tanta frecuencia? Las sospechas de los partidos comunistas europeos eran obvias: ¿puede ser realmente "marxista-leninista" un partido comunista que alude a los pensamientos e ideas de la obra de José Martí con más intensidad y frecuencia que a los "clásicos" del marxismo-leninismo?

En esta investigación de carácter colectivo, yo recibí la tarea de aportar informaciones sobre la obra política de Martí. El fruto real (y legal) de este trabajo era una selección de los escritos de Martí en húngaro (Nuestra América $)^{1}$ y algunos ensayos. ${ }^{2}$ Por este motivo desde ese período leo con gran atención la literatura científica y política sobre Martí.

* Este trabajo fue presentado en el XI Congreso Internacional de AHILA, Liverpool, 17-22 de septiembre de 1996.

1 A mi Amerikánk. Sel. de Ádám Anderle, Salvador Bueno y György Kerekes. Budapest, 1973, pág. 374 .

2 Anderle, Ádám: José Martí, a politikus. (José Martí, el Político). Budapest, 1971. 
Sin embargo, con esta tarea, para mí obligatoria, pudimos cerrar el período "infantil" de la crítica literaria húngara, utilizando la fórmula de Salvador Bueno, científico cubano que habló sobre Martí como "el Petőfi cubano", destacando su muerte heroica en el campo de batalla como motivo común de la vida de los dos poetas. ${ }^{3}$

\section{En dos trincheras}

La obra de Martí, principalmente su producción político-ideológica, provocó, y provoca, una "guerra" casi continua desde hace cien años; una guerra política en la que se utilizaron argumentos diferentes, en distintos períodos y desde posiciones políticas diversas, pero en la que el objetivo político básico es/era siempre común: dominar y expropiar exclusivamente toda la obra de Martí y presentar las corrientes adversarias como herederos injustos o ilegítimos de esta obra martiana. Apologías, odios, falsificaciones, malas intenciones, etc., son elementos básicos de esta lucha que —además de las mencionadas "calificaciones" políticas_ con todo su mal gusto nos demuestran un hecho elemental: las raíces fuertes y profundas de la obra de Martí en la memoria histórica y la conciencia nacional de Cuba.

En esta "guerra", algunas veces bastante sucia, los frentes principales podemos localizarlos actualmente entre los ideólogos cubanos y norteamericanos. Utilizo conscientemente la noción "ideólogos", y no la de "científicos", para cualificar el carácter de este debate.

De esta "rica" literatura de "guerra" quisiera mencionar y comentar dos ensayos de carácter prototípico - un artículo cubano y un ensayo norteamericano- como ilustraciones de este género.

Por lo que se refiere al primero, se trata del ensayo titulado "La batalla ideológica en torno a José Martî", publicado por un cubano, el conocido autor martiano Salvador Morales, en 1975, en el n. ${ }^{\circ} 5$ del Anuario Martiano. El segundo, opuesto aunque de título similar, 'La falsificación de José Martí en Cuba", se debe a la pluma de Carlos Ripoll y fue publicado en Pittsburg, Estados Unidos, en la revista Cuban Studies, en 1994.

En la visión de Salvador Morales existen dos "campos". El primero, el campo antimartiano, tiene carácter de "pesimismo burgués", "fatalismo absoluto", "desprecio" de Martí, "prostitución de la soberanía", etc. Este

3 Bueno, Salvador: Cinco siglos de relaciones entre Hungría y América Latina. Budapest, 1977, págs. 186-198. Sándor Petőfi fue un poeta húngaro (1823-1849) que murió en una batalla de la guerra de independencia húngara (1848-1949). 
campo "negativo" de los enemigos tiene "la tarea de neutralizar a Martî"; es decir, según Salvador Morales, este campo es proyanqui, servidor del imperialismo. El otro campo significa para él el panteón auténtico y cubano de la lucha por la independencia y por la justicia social. ${ }^{4}$

El concepto de Salvador Morales, que es también la posición oficial cubana de hoy, coloca en el panteón cubano, en el centro del arco histórico, entre Martí y Fidel Castro, la obra de Carlos Baliño y José Antonio Mella. Salvador Morales, redactor-jefe del Anuario Martiano, entre los jóvenes radicales inspirados por la obra de Martí en el período entre Mella y el Movimiento 26 de Julio, destacó a aquéllos que se movían hacia el partido comunista: Rubén Martínez Villena, Raúl Roa, Juan Marinello y Pablo Torriente Brau. Pero, en el caso de Antonio Guiteras, Salvador Morales y la posición oficial cubana nos muestran cierta ambigüedad. Lo que nos puede llamar la atención, sin embargo, es más bien el hecho de que el personaje de Antonio Guiteras no aparece en este panteón cubano constituido por Martí, Baliño, Mella y Fidel Castro.

Sin embargo, entre paréntesis, sí se puede hacer una observación personal: antes que Mella, Guiteras podría ser considerado el verdadero precursor de Fidel Castro. El partido Joven Cuba, organizado por el líder estudiantil radical, evoca el programa de Martí. Y cuando se enfrentó con el fracaso de los pocos meses de gobierno de Grau San Martín, Guiteras decidió organizar una guerrilla y, con sus compañeros, fue a México para prepararse. ${ }^{5}$ Así, Fidel Castro recibió un modelo hecho para la preparación en México, entre 1954 y 1956.

Naturalmente, en las obras de Guiteras no son éstos los elementos de la base de la mencionada ambigüedad, sino su posición no-comunista: aunque Guiteras también esbozó una visión socialista, la hace sin inspiración comunista y no en el sentido comunista. Y tampoco con la dirección del Partido Comunista Cubano (en adelante, PCC).

En el otro "campo" señalado por Salvador Morales, es decir, en la política de los EEUU, se quisiera también utilizar la obra y el nombre de Martí: una fundación, televisión y radios norteamericanas nos señalan estos intentos.

La verdad es que el interés norteamericano por la obra de Martí no era muy "intensivo" en las primeras siete décadas de este siglo: en 1979

4 Morales, Salvador: "La batalla ideológica en torno a José Martî”. Anuario Martiano, N. 5. La Habana, 1974, págs. 1-19.

5 Véase Tabares del Real, José Antonio: Guiteras. La Habana, 1973. 
todavía no existía allí ninguna monografía sobre Martí, aunque en España tampoco; si no me equivoco, el primer libro de divulgación sobre Martí en España se publicó en $1988 .{ }^{6}$

El ensayo de Cuban Studies de $1994^{7}$ rechaza las argumentaciones actuales cubanas que, según Carlos Ripoll, con el nombre de Martí "quieren justificar los abusos del poder" (“... to justify its abuses of power"). Para él, Martí es "antileninista" ("anti-leninist Martí") y por eso rechaza las tentativas oficialistas cubanas que quieren documentar "la luminosa prolongación de Martí en el pensamiento y los actos de Fidel Castro". ${ }^{8}$

En su ensayo nos presenta, por ejemplo, citas que ilustran que el PCC en los años treinta no sólo rechazó la obra de Martí sino que quiso desacreditar sus posiciones. Sin embargo, los argumentos de Ripoll no tienen gran fuerza intelectual cuando nos cita un párrafo de Juan Marinello. Según él, la cita de Marinello significa que la obra de Martí no puede "servir más que como trampolín de los oportunistas".

Con esta cita —mejor dicho, con la utilización de esta cita— tenemos dos problemas. El primero de ellos sería que Marinello en ella habla sobre el Partido Revolucionario Cubano-Auténtico, que prestó y usó el nombre del partido de Martí (PRC-Auténtico), y el segundo, que el movimiento comunista latinoamericano, sin embargo, no valoró mucho en los años treinta las ideas revolucionarias no-comunistas; a los representantes de esta corriente se los calificó como enemigos "pequeñoburgueses". Es el mismo período en el que en el Partido Comunista del Perú (en adelante, PCP), se habló sobre "las desviaciones pequeñoburguesas de José Carlos Mariátegui" ${ }^{10}$ Pero, a pesar de todo, en el PCP como en el PCC, una "corriente patriótica" de los comunistas se conectó muy estrechamente a la obra de Mariátegui y/o a la de Martí, respectivamente. Es decir, el movimiento comunista latinoamericano no era un movimiento unicolor. Además, buscando las raíces de la política actual del gobierno cubano en la posición comunista de los años treinta, podemos ver que no es una posición claramente científica ... Y, finalmente, según mi opinión, no hay que buscar el prototipo del estalinismo en la obra de Juan Marinello.

6 Según Laviana, María Luisa: José Martí. Madrid, 1992.

7 Ripoll, Carlos: "The falsificación of José Martí en Cuba". Cuban Studies, N. o 24. Pittsburg, 1994, págs. 3-49.

8 Ibídem, pág. 10

9 Ibídem, pág. 5.

10 Anderle, Ádám: Los movimientos políticos en el Peru entre las dos guerras mundiales. La Habana, 1985, págs. 313-314. 
Naturalmente, la posición cubana actual también tiene sus debilidades cuando declara que "La postura martiana (..) es un antecedente poderoso y legítimo de nuestra etapa socialista (..); la patria martiana construida por la revolución encabezada por Fidel Castro es la que lleva a todos los cubanos la obra del libertador del 95". ${ }^{11}$

Las acusaciones mutuas sobre "la utilización tendenciosa" de la obra martiana no nos ayudan en las tranquilas y equilibradas investigaciones científicas. Pero ¿cómo podemos independizarnos de este debate político?, ¿De estos cien años de guerra?

\section{Convivencia de ideas: ¿sincretismo político?}

A mí me parece que, como primer paso de esta independencia intelectual, hay que formular buenas preguntas, redactando cuestiones concretas sobre la obra de Martí. Bajo mi punto de vista, la primera cuestión posible es la siguiente: ¿por qué la influencia tan fuerte de la obra de Martí durante todo nuestro siglo?, ¿por la falta de independencia real?, ¿por la preponderancia de los EEUU en los asuntos cubanos?

Continuando con otras interrogantes, ¿hasta qué punto son correctas las argumentaciones cubanas relativas a la "herencia martiana" en la política actual y a partir de cuándo no lo son? ¿Sí, en el caso del bloqueo actual, y no en los asuntos del "socialismo" inspirado por Martí (véase la cita anterior)? ¿Dónde están los límites?

Sin embargo, creo que los cubanos de hoy tienen importantes razones para utilizar la obra martiana en la problemática de la soberanía nacional.

Siguiendo con más interrogantes, habría que plantearse otro problema, un fenómeno muy interesante y hasta hoy poco investigado. Me refiero al fenómeno de la "convivencia" de las ideas martianas y las "marxistasleninistas" en la ideología actual cubana. Esta "convivencia", ¿qué carácter tiene?, ¿cómo se caracteriza este fenómeno?

En forma de pregunta quisiera dar mi respuesta preliminar, hipotética: los contactos y lazos entre estas dos "capas" (martiana y marxista) de la ideología actual cubana ¿podríamos estudiarlos como un fenómeno típicamente cubano, tropical, como un especial "sincretismo político" donde, como en el caso de la cristianización de los indígenas, o, en el de la evan-

11 Fernández Retamar, Roberto: "Algunos problemas de una biografía ideológica de José Martî”. Latinoamérica. Anuario. Estudios Latinoamericanos, n. ํ 12, México, 1979, págs. 141-169. 
gelización de los esclavos negros, las creencias originales, autóctonas (en nuestro caso son las ideas martianas), sobrevivían discretamente tras la creencia nueva, poderosa (en el caso cubano la marxista-leninista) provocando interferencias continuas entre ambas "creencias"? Y continuando en forma de interrogación: ¿este "sincretismo" se encuentra también en el carácter del poder (actual) cubano?

Cuando se trata del poder en el caso de la Cuba socialista siempre escuchamos alusiones sobre "el carácter estalinista" o carácter comunista de la dictadura. Los cubanos también hablan frecuentemente de "la dictadura del proletariado". Yo tengo profundas dudas sobre ambas versiones. Utilizando la fórmula antes mencionada sobre el "sincretismo", veo en el poder cubano contemporáneo un producto original latinoamericano, y encuentro el parentesco más cercano en la dictadura del Dr. Francia en el Paraguay del siglo pasado. Ambos países están/estuvieron bloqueados, amenazados, y ambas dictaduras desempeñaron/desempeñan el papel de mantener y defender la soberanía y la independencia nacional, a cualquier precio.

El "culto personal" estalinista y el caudillismo carismático se "interfieren" también, creando una amalgama sincrética cubana. Sin embargo, por el papel del Estado, por la función de las organizaciones de masas (sindicatos, CDR, milicia, etc.) se presenta al Estado cubano también como un poder corporativista. En esta serie de interrogantes merecería especial atención el problema del partido martiano, el Partido Revolucionario Cubano.

En los debates políticos actuales este tema tiene un lugar central; el PCC actual pretende presentar el PRC martiano como precursor directo y, por eso, las posiciones norteamericanas presentan, con gran minuciosidad, las diferencias, las críticas de esta apología cubana. En este tema quisiera proponer otro punto de vista para entender la importancia, el carácter y la función del Partido Revolucionario Cubano.

Quisiera sugerir una hipótesis para entender el lugar del PRC en la historia política del tercer mundo, y es la siguiente: con la creación del PRC nació un tipo nuevo de partido político; no el del partido de Lenin, sino un partido de liberación nacional, prototipo del tercer mundo. Partido que tiene el mismo carácter y función que el Congress Party en la India o el Kuomintang en China (dirigido por Chan Kai Shek) y, más tarde, después de la segunda guerra mundial, el partido de Nasser en Egipto, el Front of Liberation National en Algeria, The Convention People's Party en Ghana o el Parti Democratique du Guinea. Todos los partidos de este tipo nacieron 
para organizar la lucha por la independencia, y en esta familia de partidos hay que colocar el PRC como posible prototipo.

\section{Ideas martianas: sin democracia política}

Otro tema digno de analizar es la posible conexión entre las ideas martianas y marxistas leninistas. Por ello, dejando - pero no olvidandola hipótesis mencionada sobre un posible "sincretismo" político, quisiera plantear de otro modo esta relación, pero no en la manera de Fernández Retamar, quien realizó una "operación intelectual" delicada, uniendo a Martí con el marxismo-leninismo.

Fernández Retamar encontró un cliché útil, una fórmula conocida de la historia rusa del siglo XIX sobre una corriente de demócratas-revolucionarias. Para este autor, Martí es un demócrata-revolucionario (como por ejemplo Herzen) y — como esta corriente rusa- Martí también es, según él, el precursor del marxismo-leninismo. En este sentido, según Retamar, las ideas políticas de Martí tienen "carácter de transición": "Martí no es ya (no quiere serlo) un ideólogo burgués; y no es todavía (no puede serlo) un ideólogo proletario". O, en otras palabras: "Martí, que va del radicalismo político al democrático revolucionario, del romanticismo al realismo poético". ${ }^{2}$ En el caso de Martí la analogía rusa necesitaría más investigaciones y yo no quiero seguir en este camino a Roberto Fernández Retamar.

Quisiera plantear y presentar este problema de otra manera. Existe un fenómeno obvio, y es que durante todo este siglo muchos jóvenes radicales-revolucionarios martianos llegaron al PCC. Salvador Morales nos presenta el catálogo de los nombres. Mi problema y mi pregunta es muy simple: ¿por qué los patriotas radicales cubanos con formación martiana recurrieron a menudo a las ideas también radicales y eficaces del comunismo? Por ejemplo: a Mella las ideas de Martí le parecían compatibles con las de Lenin. Pero eso también puede formularse como una experiencia más general: las generaciones de los movimientos estudiantiles cubanos basados en la plataforma radical independentista llegaron regularmente desde Martí hasta el movimiento comunista. Este hecho sugiere que la estructura y el carácter de las ideas de Martí presentaban cierta apertura (carácter abierto) en esta dirección de izquierda, comunista.

12 Ibídem, págs. 148, 150, 152. 
La respuesta directa e inmediata se explicaría con la situación neocolonial de Cuba, creando un contacto directo entre la posición antiyanqui de Martí y la del antiimperialismo comunista. Aunque esta respuesta es posible y esta posición tiene firme base histórica, quisiera plantear otra respuesta.

Esta respuesta hipotética reside en el concepto martiano de la libertad, que para él supone la libertad colectiva de una comunidad: o la nación cubana, o los negros, o América Latina, o bien los obreros o los pobres.

En su obra no surge la idea del pluralismo político, ni tampoco elaboró las normas de los derechos políticos individuales. En sus escritos no se concede a estos aspectos la importancia debida. A mí me parece que para Martí la democracia significaba en primer lugar una democracia social y no la democracia política.

Esta naturaleza del patrimonio martiano, que dejó para la posteridad los ideales de la solidaridad, igualdad, justicia, independencia nacional, que, a causa de la situación neocolonial de Cuba, siguen siendo actuales a lo largo del siglo — hasta hoy-, influyó también en las generaciones revolucionarias posteriores, casi predeterminando los acontecimientos realizados por sus discípulos.

En otras palabras, en la situación del bloqueo constante, la política cubana actual tiene en la obra de Martí una buena argumentación para defender la libertad colectiva cubana amenazada por los EEUU.

Como final podríamos decir, pues, que Cuba, por su situación expuesta a la constante amenaza de los Estados Unidos, no ha llegado hasta ahora al lujo de entender la importancia de las libertades políticas individuales. 